ARTIGOS

\title{
Pátria educadora? Uma análise das propostas para o ensino público brasileiro
}

\section{A country of education ${ }^{1}$ ? An analysis of the proposals for the Brazilian public education}

Kamila Lockmann (i)

Roseli Machado (ii)

(i) Universidade Federal do Rio Grande, Rio Grande, RS, Brasil. http://orcid.org/0000-0002-19938088 kamila.furg@gmail.com

(ii) Universidade Federal do Rio Grande do Sul, Porto Alegre, RS, Brasil. http:/ /orcid.org/0000-00015653-1175 robelmont@yahoo.com.br

Resumo: Este artigo analisa o documento Pátria Educadora: A qualificação do Ensino Básico como obra de construção nacional, em circulação desde abril de 2015 em sua versão preliminar. Para isso, utilizam-se conceitos-ferramentas de Michel Foucault, tais como discurso e governamentalidade, e olha-se para as ações propostas pelo documento para o ensino público, as quais se afinam com princípios neoliberais que regulam várias áreas, dentre elas, o campo educacional. Destacam-se a presença da Teoria do Capital Humano e a lógica do mercado incidindo sobre alunos, professores e instituições, colocando todos num jogo permanente de concorrência. Além disso, percebe-se um discurso que desqualifica professores e instituições e apresenta esse documento como capaz de salvar a educação brasileira.

Palavras-chave: políticas educacionais, ensino público, neoliberalismo, Michel Foucault

\footnotetext{
1 Sugiro esta alteração para utilizar o termo apresentado na tradução oficial do discurso inaugural do segundo mandato de Dilma Rousseff (http://www2.planalto.gov.br/acompanhe-o-planalto/discursos/discursos-dapresidenta/speech-by-the-president-of-the-republic-dilma-rousseff-brazilian-national-congress-january-1st-2015)
} 
Abstract: This article analyžes the document Pátria Educadora: A qualificação do Ensino Básico como obra de construção nacional, in circulation since April, 2015 in its draft. The focus of this paper's examination were the actions proposed by the document for the Brazilian public education. Concepts of Michel Foucault, such as discourse and governmentality, inform this discussion. From this perspective, the proposed actions are observed to be related to the characteristics of neoliberalism that regulate many areas, among them the educational field. Signs of this relation can be found in the presence of the Theory of Human Capital and the market logic operating over students, teachers and institutions putting everyone in permanent competition. In addition, the document presents a discourse that disqualifies teachers and institutions and promotes this document's project as able to save Brazilian education.

Keywords: educational policies, public education, neoliberalism, Michel Foucault

\section{Para falar em Educação}

A centralidade da Educação é um fato já estabelecido nas discussões do campo político. Quando se fala no assunto, mobiliza-se uma série de sujeitos e contextos que, inicialmente, poderiam denotar certo afastamento temático. Vemos, cada vez mais, políticos, economistas, sociólogos, filósofos, empresários, dentre outros, mostrando-se fortemente interessados em dialogar sobre o tema, que já é parte de inúmeras agendas. Não obstante, podemos dizer que a Educação, por muitas vezes, foi fundamental na propagação de certos discursos e na invenção de um tipo de sujeito, na medida em que, por seu intermédio, se racionaliza um ideal de sociedade. Desse modo, compreendemos que a Educação é concebida dentro de políticas e modos de produção de um tipo de sujeito e de um tipo de sociedade, mobilizando vários atores a participar dessa construção.

Num recuo histórico - mediante um olhar sobre a colaboração de autores do campo , destacamos o modo com que a Educação, através da escola, tem sido engendrada como protagonista para a produção de um tipo de sociedade. Veiga-Neto (2006), por exemplo, aponta que "a escola moderna funcionou - e em boa medida continua funcionando - como um conjunto de máquinas encarregadas de criar sujeitos disciplinados num e para um novo tipo de sociedade que se gestava após o fim da Idade Média” (p. 31). Nessa mesma perspectiva, Varela e Alvarez-Úria (1992) nos falam que a escola pública, gratuita e obrigatória nem sempre existiu, mas foi instituída no início do século XX, quando se adotaram medidas contra o trabalho infantil antes dos 10 anos e se transformaram os professores em 


\section{pro·posıções}

http://dx.doi.org/10.1590/1980-6248-2016-0020

funcionários do Estado. Também refletindo sobre os engendramentos da Educação nos dias de hoje, Costa (2009) nos propõe pensar a "maneira como a educação é agenciada a biopolíticas e a uma determinada forma de governamentalidade neoliberal” (p.172). Ações que visam ao governo da vida dos indivíduos e da população passam pelo campo educacional, o qual colabora para a instituição de modos de viver e para a orientação da conduta dos diversos sujeitos.

Veiga-Neto (2013b) nos explica um sentido de Educação que significa "trazer para o 'domínio de'; o que seria correlato a dominar e domesticar, sem que se coloque nessas palavras a carga pejorativa que em geral se atribui a elas" (p.4). Ou seja, podemos entender a Educação como responsável por acolher os indivíduos, trazê-los para o domínio de alguém ou de alguma coisa e conduzi-los. Nessa compreensão, destacamos que, desde sua constituição, a escola pública tem sido uma das maiores responsáveis por essa condução, tanto em relação ao contingente a que atinge quanto ao fato de ser alvo de ações do Estado que expressam, diretamente, o plano social esperado. Assim, neste caso, vamo-nos deter a tratar do ensino público como esse espaço que acolhe, educa e propõe um determinado tipo de sujeito adequado ao tempo e ao lugar em que estamos.

Em vista disso, compreendendo o protagonismo da Educação e o papel do ensino público na constituição de um ideário social, trazemos para o debate o lema proferido pelo Governo Federal Brasileiro em $1^{\circ}$ de janeiro de 2015, na ocasião do discurso de posse da presidente Dilma Roussef: "Brasil, Pátria Educadora". A partir desse discurso, podemos pensar que a presidente anuncia a Educação como uma força de verdade que está disseminada em todas as ações do Governo, perpassando todos os setores e produzindo um sujeito mais governável (Dutra \& Duarte, 2015). É a centralidade da Educação assumida por um projeto de Governo.

Problematizar a centralidade que a Educação vem assumindo nos dias de hoje é o objetivo central de uma pesquisa mais ampla, que analisa uma variedade de políticas públicas empreendidas pelo Estado brasileiro. Tais políticas se encontram vinculadas a diferentes ministérios e secretarias, mas recorrentemente convocam a Educação como instância de solução de uma variedade de problemas sociais, econômicos, de empregabilidade, entre outros. Entre esses documentos analisados, destacamos o documento Pátria Educadora: A 


\section{pro·posıções}

http://dx.doi.org/10.1590/1980-6248-2016-0020

qualificação do Ensino Básico como obra de construção nacional, produzido pela Secretaria de Assuntos Estratégicos da Presidência da República.

Para tal empreendimento procuramos analisar os discursos presentes no documento na perspectiva das ferramentas de análise monumental, estudando a formação dispersa, descontínua, mas regular desses discursos (Foucault, 2008a). Para Foucault (2001), a história nos dias de hoje transforma "documentos em monumentos" e, nesse sentido "desdobra, onde se decifravam rastros deixados pelos homens, onde se tentava reconhecer em profundidade o que tinham sido uma massa de elementos que devem ser isolados, agrupados, tornados pertinentes, inter-relacionados, organizados em conjuntos" (p. 8). Com essa intenção de considerar os discursos como algo descontínuo, mas que apresenta regularidades, escolhemos, neste momento, considerar apenas a primeira parte do documento, denominada de "A Tarefa", a qual, como já especificado, tem a pretensão de esboçar o ideário do projeto. Deixamos o documento (Brasil, 2015) falar e destacamos três aspectos para o debate, os quais, em nossa percepção, reúnem pontos interessantes. São eles:

[1] a construção de ideário que oriente a transformação pretendida; [2] a definição de elenco de ações que sinalize o caminho e identifique os primeiros passos para trilhá-lo; e [3] a organização de debate que engaje a nação na definição e execução da tarefa. (p.3)

Ao examinar os discursos no documento, colocamos as lentes teórico-metodológicas dos Estudos Foucaultianos e escolhemos a governamentalidade como a grade de análise, "como um instrumento, como uma ferramenta, como lentes que Foucault cria para trabalhar sobre um problema" (Noguera-Ramirez, 2013, p. 73). A análise dos discursos sob a perspectiva da governamentalidade nos permitiu refletir sobre os investimentos e as ações que o Governo Federal, através do documento Pátria Educadora, pretende incidir sobre o ensino público brasileiro, lançando mão de ações que eduquem e conduzam os sujeitos dentro de uma racionalidade neoliberal brasileira. Governamentalidade é entendida como uma ferramenta que permite ver "o encontro entre as técnicas exercidas sobre os outros e as técnicas de si” (Foucault, 1994, p.2). No entanto, tal ferramenta teórico-metodológica só pode ser selecionada após a análise detalhada do material e do agrupamento dos discursos selecionados para esta análise. 


\section{pro.posıções \\ $e$-ISSN 1980-6248}

http://dx.doi.org/10.1590/1980-6248-2016-0020

Além disso, na companhia de outros autores, tais como Costa (2009b), Lopes (2009), Veiga-Neto (2000, 2013b), dentre outros, que tratam do tema da Educação e da escola na contemporaneidade, afinamo-nos com a perspectiva que entende que o campo educacional está sendo pensado e colocado a serviço de um neoliberalismo. Esse ponto também está sendo considerado nesta análise.

Eis aí o ponto fulcral que irá fazer da escola uma instituição do maior interesse para o neoliberalismo. $\mathrm{Na}$ medida em que, para o neoliberalismo, os processos econômicos não são naturais, eles não devem ser deixados livres, ao acaso, nas mãos de Deus, ao contrário, tais processos devem ser continuamente ensinados, governados, regulados, dirigidos, controlados. (Veiga-Neto, 2013c, pp. 38-39).

Para apresentar e sistematizar nossas reflexões, este artigo seguirá a seguinte organização: A parte II, intitulada "Neoliberalismo brasileiro e o ensino público", apresenta nossos entendimentos sobre a racionalidade neoliberal que se estabelece no Brasil e sobre a forma como ela regula as diversas ações, em especial aquelas vinculadas ao campo da Educação, destacando a concorrência e a Teoria do Capital Humano como aspectos centrais que se materializam no ensino público. A parte III, nomeada de "Tarefas de uma Pátria Educadora", traz as nossas reflexões sobre o documento analisado, centrando a conversa nas três vertentes de ações que pretendem qualificar o ensino público. Na parte final, chamada de "Por uma Pátria Educadora?", retomamos os pontos principais da discussão e refletimos sobre as ações pensadas para diferentes sujeitos educativos e sobre os discursos que produzem um tipo de docência e uma visão sobre Educação na atualidade.

\section{Neoliberalismo brasileiro}

Se falar em neoliberalismo já é, por si só, um empreendimento bastante complexo e arriscado, sustentar a ideia da constituição de um tipo de neoliberalismo brasileiro parece ainda mais pretensioso e problemático. O fato é que, olhando para as configurações atuais do cenário brasileiro, temos trabalhado com a possibilidade de visualizar, em nosso país, traços, caraterísticas e estratégias próprias de um tipo de racionalidade já desenvolvida em outros países, tais como os Estados Unidos e a Alemanha. É sabido que Michel Foucault empreendeu um estudo bastante minucioso sobre as formas de neoliberalismo desenvolvidas nesses dois países, em seu curso "Nascimento da biopolítica", ministrado no Collège de France 


\section{pro.posıções \\ $e$-ISSN 1980-6248}

http://dx.doi.org/10.1590/1980-6248-2016-0020

em 1979. Ali o autor deixa claro que não compreende o neoliberalismo como uma teoria econômica, mas como uma forma de vida. Pensamos que tal observação é importante, pois, ao abordar a discussão sobre o neoliberalismo brasileiro, não o entendemos como um bloco fixo, uma teoria econômica que possa ser aplicada neste ou naquele país de forma estanque. Veiga-Neto (2013b) atenta para isso, quando diz que falar em neoliberalismo no contexto brasileiro

não significa dizer que exista um neoliberalismo de tamanho único, igual em todos os lugares; também não significa dizer que todos os indivíduos sejam interpelados da mesma maneira pela racionalidade neoliberal; não significa, tampouco, imaginar que tal racionalidade não se manifeste em combinação com o liberalismo (chamado) clássico ou, ao mesmo tempo, com outras racionalidades político-econômicas. Afinal, num país tão grande e heterogêneo como o nosso, é sempre preciso estar atento e levar em conta as imensas diferenças regionais, socioeconômicas e culturais que nos atravessam, de modo a evitar qualquer rotulação simplificadora bem como a importação direta de teorizações para "aplicá-las" mecanicamente em toda e qualquer situação, em todo e qualquer tempo [ênfase no original]. (p. 155)

Considerando tais observações, pretendemos levar adiante essa discussão, analisando as configurações que o neoliberalismo assume no Brasil, percebendo as proximidades e os afastamentos com princípios neoliberais que regem essa racionalidade política, econômica e social em outros países, tais como a Alemanha e os Estados Unidos. Compreendemos que uma determinada racionalidade política - como o neoliberalismo -, quando engendrada em lugares e tempos distintos, pode assumir formas variadas, com diferentes ênfases, e priorizar princípios e modos, também distintos, de governar a população. Isso não significa um valetudo, uma espécie de simplificação que compreende qualquer ação do Estado brasileiro como sendo neoliberal. Para além da diversidade que possa existir nas formas de governo neoliberais, é preciso reconhecer que há, presentes em nosso país, alguns elementos centrais dessa forma de racionalidade que vêm pautando as agendas governamentais, assim como as estratégias e as ações direcionadas ao campo da Educação. São, justamente, alguns desses elementos que podemos encontrar materializados no documento aqui analisado. Nesta seção do artigo, tentaremos mostrar alguns desses elementos neoliberais e a forma como, a partir deles, a Educação se torna algo central para a construção da nação.

Comecemos analisando um dos excertos do documento (Brasil, 2015), o qual materializa aquilo que Foucault denomina a regra máxima do neoliberalismo. 


\section{pro·posıções

http://dx.doi.org/10.1590/1980-6248-2016-0020

Nas últimas décadas nosso crescimento econômico foi alavancado pela produção e exportação de commodities e pela popularização do consumo. Milhões de brasileiros foram resgatados da pobreza.... Temos agora de fazer a travessia para outra estratégia de desenvolvimento: produtivismo includente, pautado por democratização de oportunidades econômicas e educacionais.... O objetivo, mais do que construir novas vantagens comparativas na economia mundial, é dar a cada brasileiro chance melhor para ficar de pé. (p. 4)

Ao abordar a inclusão de certos grupos da população brasileira no mundo do consumo, os ditos presentes neste excerto destacam também a necessidade social e política de democratizar as oportunidades econômicas e educacionais e assim garantir a participação de todos, por meio do que é denominado "produtivismo includente". Primeiramente, precisamos compreender que temos aí uma das principais regras do jogo neoliberal: a regra da inclusão de todos. Foucault (2008b) destaca que

a sociedade inteira deve ser permeada por esse jogo econômico e o Estado tem por função essencial definir as regras econômicas do jogo e garantir que sejam efetivamente bem aplicadas.... cabe à regra do jogo imposta pelo Estado fažer que ninguém seja excluído desse jogo [ênfase adicionada]. ( pp. 277-278)

Com as palavras de Foucault (2008b), podemos perceber que a regra geral que mobiliza o jogo econômico de um Estado neoliberal é a regra da não exclusão. Assegurar a participação de todos. Garantir o acesso de todos. Não permitir que ninguém seja excluído ou se mantenha fora do jogo. Esses princípios são os mobilizadores das políticas contemporâneas e colocam-se como condição para o funcionamento do próprio neoliberalismo. É possível dizer que o neoliberalismo não consegue funcionar e nem mesmo se sustenta, sem respeitar a regra geral da inclusão. Levando a cabo tal entendimento, é possível afirmar que todo neoliberalismo é inclusivo, pois a inclusão é condição fundamental para o seu funcionamento. Entretanto, isso não significa dizer que toda inclusão seja neoliberal. Há práticas inclusivas pautadas em outras lógicas, em outros princípios. Porém, neste caso específico, não estamos falando de qualquer inclusão, mas de uma inclusão que aparece com o atributo produtivismo. Ou seja, podemos pensar que a inclusão, aqui, esteja a serviço da lógica de mercado e pretenda incluir a todos em diferentes espaços sociais, com o intuito de produzir sujeitos economicamente ativos ou produtivos.

Assim, parece que estamos diante da emergência de uma nova noção de inclusão. Não se trata de uma inclusão institucionalizada, como a escolar, nem garantida por meio da solidariedade de terceiros (sejam pessoas ou instituições), como a inclusão social. Parece que 


\section{pro.posıções \\ $e$-ISSN 1980-6248}

http://dx.doi.org/10.1590/1980-6248-2016-0020

estamos diante de uma noção que Lockmann (2013) denominou "inclusão produtiva", um tipo "específico de inclusão que requer um investimento constante sobre o sujeito, justamente por ser ele o próprio responsável, não só por se incluir nos jogos do mercado, mas também por se manter incluído" (p. 152). Lopes (2009) diz que "é fundamental que aprendamos nesses movimentos o necessário para estarmos e permanecermos dentro das redes produtivas" (p. 156). Parece ser, justamente, esse movimento de saber entrar e de permanecer no jogo que visualizamos nos discursos apresentados pelo documento, quando enfatizam e fazem emergir a noção de inclusão produtiva como um dos imperativos do nosso tempo.

Diante disso, parece estar clara a articulação deste primeiro elemento do neoliberalismo brasileiro - a noção de inclusão produtiva ou de produtivismo includente com outros elementos provenientes, por exemplo, do neoliberalismo norte-americano. Como dito anteriormente, não se trata de compreender o neoliberalismo norte-americano como uma teoria econômica fixa e invariável a ser aplicada em território brasileiro. O fato é que as discussões empreendidas pelos economistas da Escola de Chicago acerca da Teoria do Capital Humano parecem ressoar com bastante força aqui no Brasil e materializar-se, principalmente, em políticas ou propostas educacionais.

A Teoria do Capital Humano consiste em entender um conjunto de habilidades e capacidades humanas como uma forma de capital. Segundo essa compreensão, não podemos mais perceber o indivíduo e o capital separadamente, como se fossem exteriores um ao outro. Nesse sentido, conforme lembra Costa (2009a), um executivo, por exemplo, não seria o representante do capital e, tampouco, um operário poderia ser concebido como objeto de exploração do capital. Trata-se de compreender que as habilidades, as competências, as aptidões de um indivíduo constituem, elas mesmas, o seu próprio capital. Em outros termos, o indivíduo deve tomar a si mesmo como uma empresa. Segundo López-Ruiz (2007), nessa teoria "o humano, um conjunto de capacidades, destrezas e aptidões próprias dos homens, adquire valor de mercado e se apresenta como forma de capital” (p. 18).

Temos aí a inversão do Homo cconomicus do liberalismo: podemos dizer que se passa, de um Homo cconomicus parceiro da troca - teoria da utilidade a partir da problemática das necessidades, o que caracteriza a concepção clássica de Homo cconomicus -, para um "Homo cconomicus empresário de si mesmo, sendo ele próprio seu capital, sendo para si mesmo seu produtor, sendo para si mesmo a fonte de [sua] renda" (Foucault, 2008b, p. 311). Essa 


\section{pro·posıções}

http://dx.doi.org/10.1590/1980-6248-2016-0020

transformação trata de produzir um sujeito que, a partir das suas habilidades e competências, seja capaz de gerenciar sua própria vida, tornando-se um empreendedor da sua própria existência e, por isso, produtivo. Para isso, essa forma de governamentalidade - neoliberal busca investir nos próprios sujeitos, intervir nas formas de ser, de agir, de pensar, de relacionar-se, com o intuito de aumentar a qualidade da população e, com isso, obter um maior crescimento econômico.

Assim, podemos compreender essa espécie de ampliação ou de generalização da forma econômica do mercado a âmbitos não econômicos da sociedade. Segundo Costa (2009), tratase de um "deslocamento mediante o qual o objeto de análise (e de governo) já não se restringe apenas ao Estado ou aos processos econômicos, passando a ser propriamente a sociedade, quer dizer as relações sociais, as sociabilidades, os comportamentos etc.” (p. 144). Foram os comportamentos dos sujeitos, suas formas de ser e pensar que se tornaram alvo das intervenções operadas na sociedade. Isso porque, ao qualificar a população, ao investir em seu capital humano, está-se, ao mesmo tempo, investindo também em um crescimento econômico futuro. O neoliberalismo, então, estende a racionalidade do mercado a domínios não econômicos, porém suas intervenções nesses âmbitos - tais como o sujeito, a família, a natalidade, as relações sociais, a Educação - geram efeitos econômicos, trazem benefícios ao processo econômico mediante seu crescimento.

Por esse motivo é que, na lógica neoliberal, os recursos financeiros destinados ao aprimoramento do capital humano, por exemplo, não podem ser compreendidos como gastos, mas como investimentos. Portanto, passamos de uma lógica liberal, que compreendia a Saúde, a Educação e a Assistência como atividades de consumo, para outra - a lógica neoliberal -, que as compreende como investimentos. Costa (2010) marca claramente esse deslocamento quando diz que,

para a lógica neoliberal norte-americana, o crucial não está ancorado na troca e, portanto, no homem da troca, no homem que pela troca e, consequentemente, pelo consumo, é convertido em mercadoria; em vez disso, o fator decisivo está numa produção condicionada pela concorrência.... Eis um deslocamento fundamental que não escapa aos olhos atentos de Foucault: priorizar o investimento e a concorrência, em detrimento da troca e do consumo. (p. 15)

Sendo assim, podemos compreender que essas práticas de investimento no sujeito fazem parte de uma forma de pensamento, uma racionalidade mais ampla, regulada e 


\section{pro·posıções

produzida pela própria dinâmica competitiva. Trata-se de instrumentalizar os sujeitos para que cada um possa, mesmo que minimamente, participar do jogo econômico do neoliberalismo e estabelecer relações de concorrência entre si. O que possibilita ao sujeito sua participação nos mecanismos de concorrência são, sobretudo, os investimentos que o próprio sujeito, o Estado, ou as empresas privadas realizam nas suas qualificações, habilidades e competências. Ball (2004) destaca que "cada vez mais, as políticas sociais e educacionais estão sendo articuladas e legitimadas explícita, direta e, muitas vezes exclusivamente em função do seu papel em aumentar a competitividade econômica por meio do desenvolvimento das habilidades, capacidades" (p. 1.109). Parece, dentro desse quadro, que a Educação é acionada como o campo a partir do qual se exercerão tais investimentos em capital humano, o que permitirá colher os futuros rendimentos desses para o Estado. Não é por acaso que o documento aqui analisado se chama Pátria Educadora: a qualificaşão do Ensino Básico como obra de construção nacional. Para dar ares de ser a Educação o campo responsável por construir uma nação "melhor" e mais "evoluída".

A partir disso, compreendemos que inclusão, investimentos em capital humano e concorrência são alguns dos elementos centrais que constituem o neoliberalismo brasileiro e estão pautando as propostas educacionais materializadas nesta versão preliminar do documento, o qual se nomeia como uma obra de construção nacional. Após essas breves discussões, passamos a analisar a primeira parte do documento e mostrar suas relações de imanência com a racionalidade social, política e econômica que rege nosso país na atualidade.

\section{Tarefas de uma pátria educadora}

Como já citamos, nesta parte do artigo, trazemos as problematizações sobre o documento em análise, a partir de um exame numa perspectiva monumental. Para melhor organizar nossa discussão, focamos a apreciação nas três vertentes de ações, apresentadas pelo próprio documento, que pretendem qualificar o ensino público: a construção de ideário que oriente a transformação pretendida; a definição de elenco de ações que sinalize o caminho e identifique os primeiros passos para trilhá-lo; e a organização de debate que engaje a nação na definição e na execução da tarefa (Brasil, 2015). Percebemos que são vertentes que se entrecruzam e possuem certa relação de dependência; contudo, preferimos destacá-las 


\section{pro·posıções

individualmente, evidenciando a quais pontos de um Estado neoliberal brasileiro estão vinculadas e o que isso representa para o ensino público e para os docentes.

\section{Vertente 1: A construção de ideário que oriente a transformação pretendida}

Nessa primeira linha de ação proposta pelo documento, destacamos, para iniciar, a expressão "ideário". Entendemos que há uma procura pelo fortalecimento de um discurso engendrado na episteme em que vivemos, fortemente conexa aos preceitos desse neoliberalismo brasileiro, que citamos anteriormente. Como diz o documento (Brasil, 2015), "o esforço para qualificar o ensino público surge no Brasil dentro do contexto maior: a construção de nova estratégia de desenvolvimento nacional" (p. 4). Na edificação desse ideário, as verdades são construídas e postas em circulação. O próprio documento em análise já é uma parte dessas verdades.

A partir de Foucault (2008a), entendemos que nosso pensamento se constitui dentro das possibilidades regidas por uma ordem que nos permite ver, entender e dizer certas coisas tidas como verdades. Para o autor, cada sociedade tem tipos de discurso que ela acolhe e faz funcionar como verdadeiros (Foucault, 1988). Essas verdades, objetos de ações políticas difundidas em forma de discursos nos diversos aparelhos sociais, estatais e privados, sendo produtoras e produzidas nas práticas, constituem a racionalidade de uma época, de uma sociedade. Quando vemos funcionar certos engendramentos do presente e percebemos como alguns discursos proliferam, temos que nos referir à possibilidade de compreendê-los neste tempo, nesta ordem do discurso (Foucault, 2008b). Esse entendimento se afina com o conceito de episteme:

Por episteme entende-se, na verdade, o conjunto das relações que podem unir, em uma dada época, as práticas discursivas que dão lugar a figuras epistemológicas, a ciências, eventualmente a sistemas formalizados; o modo segundo o qual, em cada uma dessas formações discursivas, se situam e se realizam as passagens à epistemologização, à cientificidade, à formalização; a repartição desses limiares que podem coincidir, ser subordinados uns aos outros, ou estar defasados no tempo; as relações laterais que podem existir entre figuras epistemológicas ou ciências, na medida em que se prendam a práticas discursivas vizinhas mas distintas. (Foucault, 2001, p. 214) 


\section{pro·posıções \\ $e$-ISSN 1980-6248}

http://dx.doi.org/10.1590/1980-6248-2016-0020

É possível pensarmos que, estando inseridos nesta episteme, as verdades que estão circulando sobre Educação neste momento passam a fazer sentido, pois são partes desse ideário ou dessa racionalidade neoliberal. Do mesmo modo, entendemos que os sujeitos imersos numa racionalidade também se constituem a partir de discursos - o que não exclui a reflexão de que é nas relações de poder que somos constituídos, como demonstrou Foucault em sua obra. O que destacamos é o entendimento de que certas produções de verdades são possíveis em determinada época, por condições de possibilidade que as sustentam e acabam atribuindo sentido às práticas que dela decorrem.

Dentre as verdades que circulam nos dias de hoje e que também se fazem presentes no documento, está a ideia de um fracasso da escola - em especial, a pública - e a falta de preparo dos professores, responsabilizando-os pela falência da Educação. No texto preliminar, por exemplo, é possível ver passagens que citam as escolas como inseridas em "redes escolares defeituosas" (Brasil, 2015, p. 7) e em "redes escolares persistentemente malogradas" (p.8), o que colabora com a ideia de um fracasso escolar que precisa ser superado e desqualifica a todos que dele fazem parte, como é o caso dos professores, que são ali caracterizados da seguinte forma:

Os professores vêm comumente dos alunos mais fracos do ensino médio. Encontram maior facilidade em ingressar nas escolas de pedagogia, sobretudo as privadas. Estudos sugerem que a maior parte dos professores no nosso ensino médio sofreu pelo menos uma reprovação. ... É voz corrente nas universidades e no professorado que os melhores alunos costumam não ficar na docência. Demonstradas suas credenciais, cedo procuram escapar para outra profissão. Dos que ficam, muitos procuram minimizar, a qualquer custo, tempo na sala de aula. Comumente preferem tarefas administrativas. Porcentagem impressionante, e sem equivalente em outro lugar do mundo, falta ao trabalho alegando doença. (Brasil, 2015, p. 16)

Diante disso, problematizamos e rejeitamos a representação docente apresentada pelo documento, a qual desqualifica e desvaloriza o trabalho dos professores do Ensino Básico, descrevendo-os de forma pejorativa e universal, como fracassados, despreparados e com formação ineficaz. O trabalho desenvolvido nas universidades públicas e privadas não passa ileso por tal documento, sendo também alvo de críticas e desqualificação, como podemos observar no excerto a seguir:

Só pequena porção [dos professores] se forma na pedagogia e nas licenciaturas das universidades federais. Estas estão longe de oferecer ensino compatível com rumo como o que aqui se propõe. Deixam-se fascinar, ao gosto de cada catedrático, com o torneio de manual 


\section{pro.posıções

http://dx.doi.org/10.1590/1980-6248-2016-0020

entre filosofias da educação. Costumam, entretanto, prover ao menos alguns elementos de formação aceitável. Não é o caso da grande maioria dos professores, formada em instituições particulares, muitas de seriedade duvidosa, dedicadas ao lucro e carentes de recursos intelectuais. (Brasil, 2015, p. 16)

Assumimos uma postura de problematização diante desses discursos, pois entendemos que nunca são neutros ou inocentes, pois produzem efeitos que incidem sobre os sujeitos e constituem verdades sobre o campo da Educação e da formação docente. Para Foucault (2014), a noção de problematização "é o conjunto das práticas discursivas ou não discursivas que faz alguma coisa entrar no jogo do verdadeiro e do falso e o constitui como objeto para o pensamento" (p. 236). Assim, entendemos que tais discursos precisam se constituir como objetos do pensamento e ser questionados, problematizados e analisados nas tramas de saberpoder-verdade que os compõem. Precisamos compreender que os discursos materializados em um documento construído pela Secretaria de Assuntos Estratégicos da Presidência da República fazem mais do que simplesmente divulgar ou descrever a realidade do Estado brasileiro. Por meio das verdades que produzem, esses discursos realizam processos de subjetivação nos sujeitos, construindo nossas representações e compreensões acerca do contexto educacional de nosso país. Não é à toa que recorrentemente escutamos: "a Educação no Brasil vai mal", "os professores não estão preparados", "as escolas estão sucateadas"; ou somos informados de que há índices insatisfatórios de aprovação ou de desempenho do alunado, entre outros discursos tão recorrentes na atualidade. Não estamos com isso desconsiderando os problemas existentes no campo da Educação, porém precisamos atentar para o perigo de universalizar determinadas representações docentes e discentes, como sendo únicas e verdadeiras, esquecendo os efeitos de verdade que elas produzem sobre todos nós.

A partir da compreensão de Foucault, os discursos fazem mais do que simplesmente utilizar signos para designar coisas. Para ele, discurso-poder-verdade se articulam constantemente, numa trama que produz efeitos sobre o sujeito, ou seja, trata-se de "um certo número de expressões que não farão outra coisa que repercutir essas verdades naqueles que são governados" (Foucault, 2010, p. 45). Assim, pela simples divulgação e circulação desses discursos, realizam-se processos de subjetivação nos sujeitos, fazendo-os desenvolver um tipo de governamento que incide sobre seus próprios corpos, almas, pensamentos, opiniões e compreensões acerca da Educação brasileira. Ou seja, realizam-se determinados atos sobre si 


\section{pro.posıções}

http://dx.doi.org/10.1590/1980-6248-2016-0020

mesmos - são levados a operar sobre si a partir das verdades produzidas numa determinada época.

Obviamente isso não implica uma ausência de resistência, de escape ou de contraconduta. Foucault (2012) diz que "em qualquer relação humana, sejam elas pessoais, institucionais e/ou econômicas, o poder está presente"; mas, ao mesmo tempo, alerta: "Toda relação de poder implica a possibilidade de resistência, escapatória, fuga, reversibilidade de comando" (p. 269). Isso significa compreender que os processos de subjetivação contemplam práticas de liberdade e que cada sujeito, a partir das relações que estabelece consigo mesmo e das ações que desenvolve sobre si, tem a possibilidade de legitimar o poder político ou de resistir e reinventar outras formas de ser governado e de governar a si mesmo. Talvez seja esse o movimento que tentamos fazer aqui: olhar para tais discursos com suspeita, com resistência e desconfiança. Trata-se de problematizar, ou, nas palavras de Nietzsche (1988), de lançar, para tais discursos, um "mau olhado" e um "mau ouvido" (p. 12). Lançar um "mau olhado" e um "mau ouvido", no sentido nietzscheano, possibilita justamente o estranhamento daquilo que é tomado como verdade do nosso tempo.

Nesta primeira seção analítica de nosso texto, percebemos as verdades produzidas acerca da Educação e dos professores e que constituem o chamado ideário que orientará a transformação pretendida. A partir desse movimento de desqualificação da Educação, dos professores e das universidades, sejam elas públicas ou privadas, são trazidas soluções milagrosas, como a parceria com empresas privadas, maior investimento em capital humano e ampliação da concorrência, dentre outras ações desse nosso neoliberalismo brasileiro, ditas capazes de resolver os problemas aqui apontados.

$\mathrm{Na}$ vertente a seguir, focaremos nas ações previstas no documento. Mas, para além disso, também já gostaríamos de destacar a construção de uma subjetividade docente que vai se desenhando e se constituindo a partir desses discursos que põem o professor em um lugar menor. Como ele é tido como desqualificado, oriundo de fracassos escolares e mal preparado, nessa perspectiva, deve deixar que outros - como parcerias privadas, economistas, sociólogos, administradores, etc. - ocupem o seu lugar na tarefa de planejar o ensino e decidir os rumos da Educação no Brasil. Aprofundaremos essa relação na terceira vertente. 


\section{pro-posıções \\ Vertente 2: A definição de elenco de ações que sinalize o caminho e identifique os primeiros passos para trilhá-lo}

Se, na primeira vertente, visualizamos a proliferação de verdades que desqualificam a Educação, apontando as mazelas que rondam o trabalho docente desenvolvido nas escolas de Educação Básica e nas universidades, na continuidade do documento encontramos uma série de ações que se propõem a qualificar o ensino básico e a salvar não só a Educação, mas também a nação brasileira. Eis o paradoxo: por um lado, temos a Educação e suas mazelas; por outro, encontramos a Educação e seus milagres, os quais serão atingidos por meio de determinadas ações. Entre elas, podemos destacar: organização de um sistema nacional de avaliação para os alunos; procedimentos corretivos para as escolas; uso de boas práticas como exemplos a serem alcançados; criação de um currículo com sequências especiais para os alunos que enfrentam maior dificuldade ou apresentam maior potencial; premiação de escolas; intervenção junto aos diretores; implantação da Prova Nacional Docente, entre outros.

Contudo, em ambos os casos há um forte investimento no sujeito, que, como dissemos, precisa entrar, permanecer e, mais ainda, desejar permanecer no jogo. Para isso, a Educação é acionada para que se invista em cada sujeito, para que se invista em seu capital humano. Ao planejar um currículo, ao investir em avaliação e ao destacar boas práticas, também estamos, de certo modo, procurando estratégias para qualificar cada sujeito, para que ele se torne, também, uma fonte de rendimentos no jogo, um empresário de si mesmo que responde dentro do desejado para si e para os outros. Com isso, não queremos dizer que não devemos investir nos sujeitos através da Educação, mas refletimos sobre o tipo de investimento que está sendo realizado e sobre o sujeito que desejamos formar.

Por exemplo, ao olharmos para a maioria das ações que o documento traz, percebemos que um dos grandes investimentos em curso é para que haja, cada vez mais, sujeitos concorrentes, capazes de competir. A premiação das escolas e a implantação de "escolas modelo", que todos deverão tentar alcançar, são ações que vão ao encontro dessa lógica concorrencial. Isso pode ser claramente visualizado no excerto a seguir:

Há duas maneiras de criar oportunidades especiais para os alunos com maior potencial. Não se contradizem; complementam-se. Uma é criar programas especiais dentro das escolas comuns. Outra é fundar rede federal de escolas médias de referência chamadas Escolas Anísio Teixeira. Alunos concorrerão para serem admitidos a estas escolas. (Brasil, 2015, p.11) 


\section{pro·posıções \\ $e$-ISSN 1980-6248}

http://dx.doi.org/10.1590/1980-6248-2016-0020

Visualizamos aqui um movimento de incentivo à competição que deverá ser travada entre alunos, para que possam frequentar as escolas modelos. Por esse viés, poderíamos pensar que essas ações são totalmente excludentes, deixando de fora uma massa de alunos que não conseguiram atingir determinados patamares de exigência para ingressar em tais escolas. Porém, não nos esqueçamos de que a regra máxima do neoliberalismo é justamente oposta a isso: trata-se da regra da não exclusão. Ao retomarmos nossas considerações sobre a constituição de um neoliberalismo brasileiro, percebemos que suas características estão presentes nas ações do documento. Quando se fala em um currículo que seja diferenciado para alunos considerados com aptidões ou capacidades diferentes, está se falando em inclusão. Nessa perspectiva, é importante que todos estejam no jogo, mas, como afirma Lopes (2009), as posições nesse jogo são diferentes. Ao mesmo tempo, isso é produtivo, pois cada um desses sujeitos responde a uma finalidade que serve para o jogo econômico. Não importa se todos terão o mesmo ensino, importa que estejam incluídos e respondam a esse chamado produtivismo includente. Esta lógica aparece materializada no documento (Brasil, 2015):

A insistência em incorporar ao ensino oportunidades acadêmicas extraordinárias para os que possam aproveitá-las combina com outras iniciativas propostas neste ideário para exemplificar um compromisso: o de sacudir a mediocridade. Não se sacode a mediocridade apenas para acomodar elite de talentosos. Sacode-se a mediocridade, é certo, para impedir que nossos Newtons e Darwins continuem a baixar à sepultura sem se haverem reconhecido. Mas sacodese a mediocridade, também, para levantar a todos. Os que não quiserem ou conseguirem, em primeiro momento, admissão aos programas especiais ou às escolas de referência seriam prejudicados pela negação de oportunidades a alunos com potencial extraordinário. Seriam empurrados para baixo, como são agora, pela supressão de fontes de inspiração no sistema de ensino, ao mesmo tempo que a nação é empobrecida pela rendição à mediocridade, travestida de compromisso igualitário.... A solução não está em impedir a variação do ensino e em impor a mediocridade em nome da democracia. Está em usar os programas especiais para subsidiar a transformação dos programas gerais. Está também em tomar medidas pró-ativas para identificar vocações incomuns na massa de estudantes pobres e prepará-los para candidatar-se às escolas de referência e às sequências curriculares especiais. (p.12)

Porém, essa lógica da competição que regula o neoliberalismo não atinge somente as escolas e os alunos. Também os professores serão convocados a atender esse chamado, dada a importância com que está sendo apresentada a Prova Nacional Docente, a qual está sendo vista como um "complemento da carreira nacional de professor" (Brasil, 2015, p. 18). Parecenos que o professor que desejar evoluir na carreira docente deverá continuar permanentemente investindo em seu capital humano e, por que não dizer, concorrendo com seus pares e com ele mesmo. Eis a meritocracia se fazendo presente: 


\section{pro.posıções

http://dx.doi.org/10.1590/1980-6248-2016-0020

A carreira nacional será vinculada ao piso salarial. E o piso salarial será definido de maneira a respeitar as diferenças regionais e a permitir em cada região progressão adequada na carreira. Esta carreira pode ser construída em etapas. Ela pode começar na forma de carreira especial e suplementar para professores que se comprometam a manter determinadas metas de desempenho. Receberiam adicional ao salário, depois de avaliação, por avaliadores independentes, do cumprimento de tais metas. (Brasil, 2015, p. 18)

Além de toda a lógica empresarial, regulada por méritos, premiações e punições, que se faz presente no documento, não podemos deixar de perceber que essas avaliações, tais como a Prova Nacional Docente, não se constituem apenas em instrumentos para medir a competência ou as capacidades e as habilidades dos professores recém-formados. Além disso, elas produzem implicações na construção e na implementação dos currículos dos cursos de formação docente, o que é claramente exposto pelo documento (Brasil, 2015) como algo positivo e necessário, quando destaca:

[A Prova Nacional Docente] exigiria de todos os professores demonstrar que estão preparados para ensinar nas áreas para as quais se credenciam. E, por isto mesmo, junto com as outras iniciativas descritas em seguida, serviria como meio poderoso de influir nos cursos de pedagogia e de licenciatura. (p. 18)

Esse movimento de regulação dos currículos por meio das avaliações em larga escala já é amplamente discutido na Educação Básica a partir de uma variedade de provas. Porém, parece que esse mesmo efeito de regulação dos currículos chega agora às universidades, com a pretensa criação da Prova Nacional Docente. Veiga-Neto (2013a) destaca que atualmente há um deslocamento das práticas curriculares no sentido de privilegiar a avaliação.

Recorrendo ao sequenciamento curricular que sai do planejamento, passa pela execução e chega à avaliação, pode-se dizer que atualmente estamos assistindo a um forte deslocamento de ênfase para o lado direito dessa sequência. Em outras palavras, estamos assistindo a um desvio à direita. (p.12)

Com a expressão "desvio à direita", o autor pretende ressaltar não apenas um deslocamento de ênfases, mas também e ao mesmo tempo, uma reorganização da sequência tradicional das operações curriculares. $\mathrm{O}$ autor mostra que a antiga sequência planejamentoexecução-avaliação parece modificar-se na atualidade e acaba sendo organizada de outro modo, o qual inicia pela avaliação: avaliação-planejamento-execução. É a avaliação que passa a determinar o planejamento e a sua execução. Dessa forma, Veiga-Neto (2013a) destaca que a avaliação tem se tornado um farol para o currículo. Ou seja, tomando como exemplo a Prova 


\section{pro·posıções

Nacional Docente, a partir da sua estrutura e do que será privilegiado em termos de conteúdos a serem avaliados, ela determinará o que deverá ser trabalhado no currículo dos cursos de formação de professores, assim como conduzirá e regulará a ação docente dos professores universitários.

Ainda nesta segunda seção, colocamos em pauta um aspecto importante presente no documento, quando ele se refere ao talento e à mediocridade. É interessante destacar aqui a reconfiguração que palavras como "talento" assumem numa racionalidade neoliberal. Por um lado, o excerto analisado nos leva a compreender talento como aptidão natural, dom ou habilidade que precisa ser reconhecida. Se, por um lado, parece haver uma ênfase no talento como uma aptidão natural do sujeito, por outro lado, recorrentemente, encontramos nos discursos analisados a necessidade de investir constantemente nos sujeitos e em seu capital humano. À primeira vista esses movimentos podem parecer contraditórios, mas é importante lembrar que, nos estudos de Foucault (2008a) sobre a Teoria do Capital Humano, ele nos deixa claro que os economistas da Escola de Chicago dividem o capital humano em dois grupos: os elementos inatos e os elementos adquiridos. Assim, permanecem as compreensões sobre habilidades e competências como algo inato e se agrega uma necessidade de investir no sujeito para aprimorar seu capital humano. Talvez, por meio desses movimentos, possamos visualizar a forma como expressões mais antigas, como "talento", "dom", "aptidão natural", se articulam com uma nova racionalidade política, econômica e social que se pauta pela concorrência entre os sujeitos e por isso precisa investir constantemente neles, com o intuito de retirá-los da mediocridade.

$\mathrm{Na}$ próxima seção, analisaremos a convocação incessante, dirigida a todos os membros da sociedade, para que se engajem neste projeto de "transformação nacional".

\section{Vertente 3: A organização de debate que engaje a nação na definição e na execução da tarefa}

Para a grande maioria dos estudiosos políticos, o neoliberalismo é uma teoria econômica segundo a qual visualizamos a ausência do Estado e a partir da qual se materializa aquilo que tem sido chamado Estado Mínimo. Já destacamos que não compreendemos o 


\section{pro·posıções \\ $e$-ISSN 1980-6248}

http://dx.doi.org/10.1590/1980-6248-2016-0020

neoliberalismo como uma teoria econômica, ou seja, um corpo teórico próprio constituído por princípios originais e coerentes. Antes disso, entendemos o neoliberalismo como um conjunto heterogêneo de proposições práticas. É muito mais, como ensinou Foucault (2008b), uma forma de vida do que uma teoria econômica. Em segundo lugar, precisamos lançar um olhar de desconfiança para essa compreensão naturalizada de Estado Mínimo, ou da ausência do Estado. De acordo com Lopes (2009), “o abrandamento da presença do Estado não significa o seu desaparecimento; ao contrário, significa a sua presença em cada prática institucionalizada ou não" (p. 166). Isso significa dizer que o Estado, no lugar de desaparecer, prolifera na sociedade, estabelecendo parcerias e se fazendo presente em diferentes instâncias sociais. Ora, se entendemos o Estado como um ponto único, irradiando seu poder a partir de uma instância localizada, então é possível falarmos em enfraquecimento, diminuição ou desaparecimento do Estado. Nessa lógica, cabe falar de Estado Mínimo. Mas, se entendemos que vivemos em um Estado governamentalizado, onde as ações, as intervenções e as práticas de governamento se espalham pelo tecido social, circulando em diferentes pontos e instâncias da sociedade e convocando a todos para exercer a tarefa de governar, nesse caso, não cabe falar em um Estado Mínimo no neoliberalismo.

Assim, numa perspectiva foucaultiana, o neoliberalismo não representa a vitória liberal do horror ao Estado. Ao contrário do que muitos têm dito - aí incluídos economistas políticos, sociólogos e a mídia -, não há nem mesmo o retrocesso do Estado, uma diminuição do seu papel. O que está ocorrendo é uma reinscrição de técnicas e formas de saberes. (Veiga-Neto, 2000, p. 198)

É importante destacar que esse modo de vida neoliberal, esse Estado governamentalizado, não se afasta de ações que servem ao mercado. Diferente do que acontecia no liberalismo, em que se buscava deixar o Estado fora para o mercado conduzir, no neoliberalismo o Estado é constantemente acionado e está a serviço do mercado (CastroGomez, 2010). Assim, podemos entender as parcerias que se estabelecem entre Estado e empresas privadas, ONGs e outras instituições, para incluir os diversos sujeitos no jogo econômico e garantir a manutenção dessa forma de vida neoliberal. Faz sentido, nessa perspectiva, que todos assumam e trabalhem em prol dos mecanismos que a sustentam e divulguem suas ideias. Em se tratando da constituição do que significa a Educação, o documento que analisamos estabelece - como já citamos - um tipo de Educação que reforça as prerrogativas de um Estado neoliberal, como a concorrência, o investimento em capital 


\section{pro·posıções}

http://dx.doi.org/10.1590/1980-6248-2016-0020

humano, a inclusão dos sujeitos nas redes de mercado, dentre outros. Mas, para além disso, também convoca a todos para assumir esse compromisso, buscando parcerias e engajamento de todos os sujeitos.

Projeto deste alcance não pode ser executado por autoridades e visionários se não tiverem por aliado um movimento com presença em muitas partes da rede pública e do país. Professores e diretores da rede pública e militantes da sociedade civil, teóricos da educação e reformadores práticos podem juntos compor esta linha de frente, capaz de convergir em torno da agenda.

É comum que uma iniciativa transformadora ajude a construir sua própria base de apoio. Menos comum, e mais difícil, é ter de ajudar a fabricar seu próprio agente. É isto, porém, o que terá de acontecer para que tenha êxito o projeto. Há simpatia latente dentro e fora da rede pública de ensino por iniciativa arrojada como a que aqui se esboça. Nenhuma outra causa iguala a da educação no potencial para entusiasmar e para unir a nação. $\mathrm{O}$ anúncio da intenção transformadora, a defesa do ideário e a realização dos primeiras medidas servirão como chamamento a muitos para juntar-se ao movimento. (Brasil, 2015, p.20)

Desse modo, quando a Secretaria de Assuntos Estratégicos da presidente Dilma Roussef convoca a nação para se engajar em prol de uma melhoria da Educação, isso não significa que o Estado esteja recuando, mas mostra as parcerias que se pretende estabelecer. É por meio delas que o Estado se ramifica pelo social, fazendo-se presente em cada prática, em cada sujeito. Esse é um Estado governamentalizado.

Ao longo de todo o documento, observa-se uma chamada incessante para que todos se engajem nesse projeto que qualificaria o ensino no Brasil. No excerto aqui destacado, temos um exemplo desse movimento que convoca a todos. Nessa ordem, a chamada transcende os muros da escola e se espalha para os diversos segmentos sociais. Não basta que se constitua um discurso, ele deve ser assumido por todos, estabelecendo-se como uma verdade que convence e conduz.

Essas verdades, produzidas por toda uma rede discursiva que se estabelece, vai, de certo modo, subjetivando os sujeitos que as aceitam e as assumem. Todavia, o que problematizamos é que verdades são essas que chegam até os sujeitos e os convocam. Como vimos no desenrolar do documento, são discursos que desqualificam os professores, depreciam as escolas e as universidades, estabelecem uma meritocracia e primam pela concorrência. Quando, pelo constrangimento a esses discursos, os sujeitos assumem a convocatória estabelecida pelo Estado, estão, também, reforçando esse discurso. 


\section{pro·posıções \\ $e$-ISSN 1980-6248}

http://dx.doi.org/10.1590/1980-6248-2016-0020

Retomamos, com esta terceira vertente, o entrelaçamento entre as três. A primeira vertente traz o ideário que está sendo construído e a racionalidade na qual se estabelece; já a segunda mostra quais são as estratégias a serem seguidas para concretizá-lo; e a terceira põe em operação formas de convocação que atinjam os sujeitos e os subjetivem a engajar-se nesse processo de mudança.

\section{Por uma pátria educadora?}

Ao finalizarmos nossas reflexões sobre o documento Pátria Educadora, retomamos três pontos que ainda merecem ênfase. O primeiro deles é o fato de o documento apresentar essas ideias como salvadoras dos ditos problemas da Educação (Machado \& Lockmann, 2014). O que ressoa no desenrolar do seu texto é o modo como essa proposta seria a grande solução para o ensino brasileiro, pois, além de se apresentar como uma "obra de libertação e de construção nacional” (Brasil, 2015, p. 20), desqualifica toda e qualquer iniciativa já realizada. Registramos que nosso modo de problematizar essas questões se insere na esteira de pensamento que se propõe a estudá-las, sem assumir que tenham uma "missão salvacionista" (Veiga-Neto, 2003) para resolver aquilo que seria uma crise do ensino e da escola no Brasil.

Sentimos que a escola está em crise porque percebemos que ela está cada vez mais desencaixada da sociedade.... o mundo mudou e continua mudando, rapidamente, sem que a escola esteja acompanhando tais mudanças. Com isso, não estou sugerindo que ela deveria ter mudado junto; estou apenas reconhecendo um descompasso que acabamos sentindo como uma crise. (p. 110)

Nessa medida, diferentemente do que afirma o referido documento, não há crise para ser resolvida ou ensino para ser salvo. Contudo, ao focar a atenção brasileira para a Educação, chamando a todos para resolver essa dita crise, o texto ressignifica o que se pensa sobre o ensino, o professor, o aluno e a Educação. Lockmann (2016) nos fala de um alargamento das funções da escola e mostra que temos um ímpeto pelo governamento do social, em que a Educação se torna uma parceira importante.

Em segundo lugar, discutimos as diferenças de ensino ali pensadas para o que seriam dois tipos de alunos: aqueles que conseguiriam acessar as melhores escolas e aqueles para os quais a capacitação e a disciplina seriam indispensáveis, já que não teriam condições de 


\section{pro·posıções}

http://dx.doi.org/10.1590/1980-6248-2016-0020

progredir. O documento propõe currículos diferentes, partindo do pressuposto de que uns tenham mais condições do que outros.

Trata-se de trabalhar no terreno de capacitações pré-cognitivas que faltam a crianças saídas da pobreza mais comumente do que faltam aos filhos da classe média. Estas capacitações não trazem bondade: trazem poder. Empoderam os maus tanto quanto os bons. São capacitações de comportamento tanto quanto de consciências. Dois conjuntos destas capacitações merecem atenção maior: as de disciplina e de cooperação. (Brasil, 2015, p. 13)

Aproveitamos o excerto e concordamos que está se falando em questões de poder, mas não do modo como é citado no documento. Aliamo-nos ao pensamento de Foucault para compreender que existem relações de poder, e que, além disso, ao selecionar currículos diferentes para alunos considerados com capacidades desiguais, também estamos realizando operações de poder. Silva (2001) ressalta que o currículo é algo que produz seu próprio objeto e é inseparável da trama linguística. É produzido dentro de um contexto específico, atende a determinada época e deve ser entendido para além dos conhecimentos. Ele é aquilo em que nos tornamos - questão de identidade e de subjetividade. Assim, quando dizemos que os alunos são diferentes e elaboramos currículos distintos para cada um, estamos constituindo sujeitos distintos, e isso não é uma escolha aleatória, mas engendrada em operações de poder sobre cada indivíduo e, mais precisamente, em práticas de in/exclusão.

Ademais, como terceiro ponto e concluindo esta problematização, destacamos o paradoxo existente no documento, ao preconizar uma Pátria Educadora e, em suas primeiras afirmações, desqualificar os docentes, a escola e a universidade. Parece-nos que este seria o momento de valorizar e potencializar as ações dos sujeitos e das instituições que há tempos trabalham, pesquisam e atuam no cenário educacional. Em contrapartida, o que se vê são chamadas para que profissionais de todas as ordens assumam a tarefa de qualificar o ensino brasileiro, buscando parcerias privadas e divulgando saberes que constituem o ideário neoliberal que se quer reforçar.

Parece-nos fundamental considerar que a condição de possibilidade posta pelo documento para essa convocação de todos os sujeitos sociais como responsáveis por um projeto de Educação nacional envolve justamente sua afirmação da desqualificação dos profissionais da Educação. No momento em que são descritos os professores como desqualificados, as escolas como instituições defeituosas e as universidades como carentes de 


\section{pro.posıções}

http://dx.doi.org/10.1590/1980-6248-2016-0020

recursos intelectuais, não só se desqualificam os profissionais da Educação, como se abre um perigoso campo para o chamamento de todos - ou de qualquer um - para engajar-se em tal proposta salvacionista da nação e efetivar tais práticas educativas.

Diante do quadro atual, só nos resta aprender aquela postura de suspeita e problematização que Foucault (1995) nos ensinou: "Minha opinião é que nem tudo é ruim, mas tudo é perigoso, o que não significa exatamente o mesmo que ruim. Se tudo é perigoso, então temos sempre algo a fazer" (p. 256)

\section{Referências}

Ball, S. (2004, setembro/dezembro). Performatividade, privatização e o pós-estado de bemestar. Revista Educação e Sociedade, 25(89), 1.105-1.126. Retirado em 28 de janeiro de 2011, de <www.cedes.unicamp.br>.

Brasil. (2015, 22 de abril). Pátria educadora: a qualificaşão do Ensino Básico como obra de construção Nacional. Brasília: Secretaria de Assuntos Estratégicos da Presidência da República.

Castro-Gomez, S. (2010). Historia de la gobernamentalidad: razón de Estado, liberalismo y neoliberalismo em Michel Foucault. Bogotá: Siglo del Hombre Editores; Pontificia Universidad Javeriana - Instituto Pensar; Universidad Santo Tomás de Aquino.

Costa, S. G. (2009a). Biopolitica, governamentalidade e educação: introducão e conexões a partir de Michel Foucault. Belo Horizonte: Autêntica.

Costa, S. G. (2009b). Governamentalidade neoliberal, teoria do capital humano e empreendedorismo. Educação \& Realidade, 1(1), 171-186.

Costa, S. G. (2010). Governamentalidade (neo)liberal, concorrência, empreendedorismo e educação: uma abordagem foucaultiana. In XI Simpósio O (des)governo biopolítico da vida bumana. São Leopoldo: Unisinos.

Dutra, I., \& Duarte, D. (2015). Do país rico, sem pobreza, para uma pátria educadora. In Anais do V Colóquio Latino-Americano de Biopolítica. São Leopoldo: Unisinos.

Foucault, M. (1988). História da sexualidade I: a vontade de saber. Rio de Janeiro: Graal. 


\section{pro.posıções}

http://dx.doi.org/10.1590/1980-6248-2016-0020

Foucault, M. (1994). As técnicas de si. In M. Foucault, Dits et écrits (Vol. 4, pp. 783-813, K. Neves \& W. F. do Nascimento, trads.). Paris: Gallimard. Recuperado em 10 de setembro de 2015 , de http://revistas.pucsp.br/index.php/verve/article/viewFile/5017/3559.

Foucault, M. (1995). Sobre a genealogia da ética: uma revisão do trabalho. In P. Rabinow, \& H. Rabinow, Michel Foucault: uma trajetória filosófica (para além do estruturalismo e da bermenêutica) (pp. 253-278). Rio de Janeiro: Forense Universitária.

Foucault, M. (2001). A arqueologia do saber (6a ed.). Rio de Janeiro: Forense Universitária.

Foucault, M. (2008a). A ordem do discurso. São Paulo: Loyola.

Foucault. M. (2008b). Nascimento da biopolítica: curso no Collège de France: 1978- 1979. São Paulo: Martins Fontes.

Foucault, M. (2010). Do governo dos vivos: curso no Collège de France: 1979-1980: excertos. São Paulo: Centro de Cultura Social; Rio de Janeiro: Achiamé.

Foucault, M. (2012). A ética do cuidado de si como prática de liberdade. In M. Foucault, Ditos e escritos: ética, sexualidade, política (Vol. V, 3a ed., pp. 267-278). Rio de Janeiro: Forense Universitária.

Foucault, M. (2014). O cuidado com a verdade. In M. Foucault, Ditos \& Escritos V: Ética, sexualidade, política (pp. 232-243). Rio de Janeiro: Forense Universitária.

Lockmann, K. (2013). A proliferação das políticas de assistência social na educaşão escolarizada: estratégias da governamentalidade neoliberal. Tese de Doutorado, Universidade Federal do Rio Grande do Sul, Porto Alegre, Brasil.

Lockmann, K. (2016). A educacionalização do social e as implicações na escola contemporânea. Educação Unisinos (on-line), 20(1), 58-67.

Lopes, M. C. (2009, maio/agosto). Políticas de inclusão e governamentalidade. Educação e Realidade, 34(2), 153-169.

López-Ruiz, O. (2007). Os executivos das transnacionais e o espirito do capitalismo: capital bumano e empreendedorismo como valores sociais. Rio de Janeiro: Azougue.

Machado, R. B., \& Lockmann, K. (2014). Base Nacional Comum, escola, professor. ECurriculum, 12(3), 1.591-1.613. 


\section{pro.posições}

http://dx.doi.org/10.1590/1980-6248-2016-0020

Nietzsche, F. (1988). O crepuisculo dos ídolos. Lisboa: Edições 70.

Noguera-Ramirez, C. (2013). A governamentalidade nos cursos do professor Foucault. In G. Branco, \& A. Veiga-Neto (Orgs.), Foucault, filosofia e política (1a reimp., pp. 71-80). Belo Horizonte: Autêntica.

Silva, T. T. da. (2001). Documentos de identidade: uma introducão às teorias do curriculo (2a ed.). Belo Horizonte: Autêntica.

Varela, J., \& Alvarez-Uria, F. (1992). A maquinaria escolar. Teoria e Educaşão, 6, 68-96.

Veiga-Neto, A. (2000). Educação e governamentalidade neoliberal: novos dispositivos, novas subjetividades. In G. C. Branco, \& V. Portocarrero (Orgs.), Retratos de Foucault (pp. 179- 217). Rio de Janeiro: Nau.

Veiga-Neto, A (2003). Pensar a escola como uma instituição que pelo menos garanta a manutenção das conquistas fundamentais da Modernidade. In M. V. Costa, A escola tem futuro? (pp. 103-126). Rio de Janeiro: DP\&A.

Veiga-Neto, A. (2006). Dominação, violência, poder e educação escolar em tempos de Império. In M. Rago, \& A. Veiga-Neto (Orgs.), Figuras de Foucault (pp.13-38). Belo Horizonte: Autêntica.

Veiga-Neto, A. (2013a). Delírios avaliatórios: o currículo desvia para a direita ou um farol para o currículo. In A. M. P. Favacho, J. A. Pacheco, \& S. R. Sales, Currículo: conhecimento e avaliação - divergências e tensões (pp. 155-175). Curitiba: CRV.

Veiga-Neto, A. (2013b). Estudos de biopolítica e educação na América Latina: avaliação e perspectivas. In IV Coloquio Latinoamericano de Biopolitica - CLAB - e II Coloquio Internacional de Biopolítica y Educación - CIBE (pp. 1-20). Bogotá, Colômbia.

Veiga-Neto, A. (2013c). Governamentalidades, neoliberalismo e educação. In G. C. Branco, \& A. Veiga-Neto (Orgs.), Foucault, filosofia e politica (1a reimp. pp. 37-52). Belo Horizonte: Autêntica.

Submetido à avaliação em 01 de abril de 2016; revisado em 25 de outubro de 2016, aceito para publicação em 09 de janeiro de 2017. 